
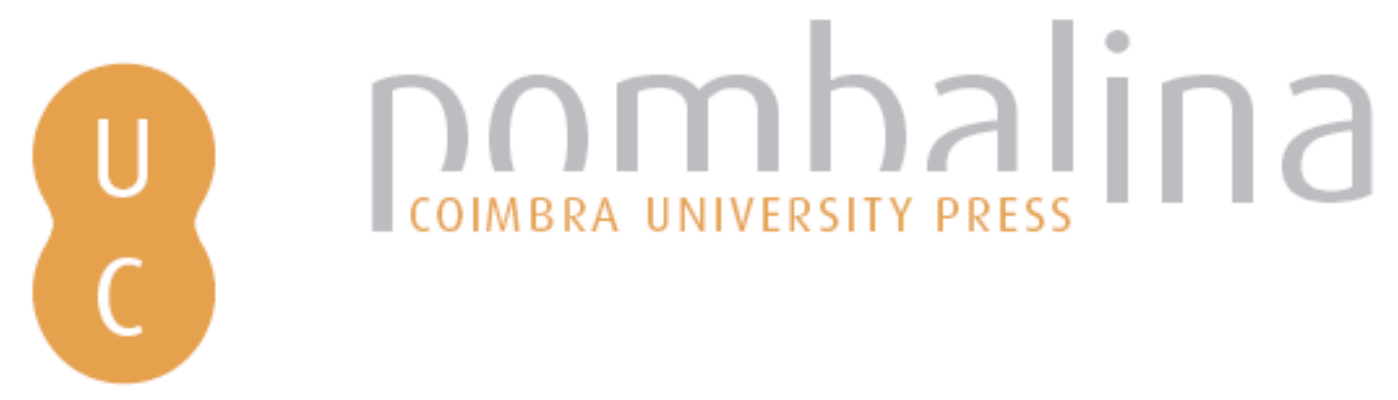

Matemática e ambiente: a redescoberta dos fundamentos básicos

Autor(es): $\quad$ Borrego, C.; Miranda, A. I.; Lopes, M.; Costa, A. M.

Publicado por: Imprensa da Universidade de Coimbra; Gravida

URL

persistente: $\quad$ URI:http://hdl.handle.net/10316.2/32599

DOI: $\quad$ DOI:http://dx.doi.org/10.14195/978-989-26-0485-5_9

Accessed : $\quad$ 26-Apr-2023 13:10:36

A navegação consulta e descarregamento dos títulos inseridos nas Bibliotecas Digitais UC Digitalis, UC Pombalina e UC Impactum, pressupõem a aceitação plena e sem reservas dos Termos e Condições de Uso destas Bibliotecas Digitais, disponíveis em https://digitalis.uc.pt/pt-pt/termos.

Conforme exposto nos referidos Termos e Condições de Uso, o descarregamento de títulos de acesso restrito requer uma licença válida de autorização devendo o utilizador aceder ao(s) documento(s) a partir de um endereço de IP da instituição detentora da supramencionada licença.

Ao utilizador é apenas permitido o descarregamento para uso pessoal, pelo que o emprego do(s) título(s) descarregado(s) para outro fim, designadamente comercial, carece de autorização do respetivo autor ou editor da obra.

Na medida em que todas as obras da UC Digitalis se encontram protegidas pelo Código do Direito de Autor e Direitos Conexos e demais legislação aplicável, toda a cópia, parcial ou total, deste documento, nos casos em que é legalmente admitida, deverá conter ou fazer-se acompanhar por este aviso. 
(Página deixada propositadamente em branco) 
MARIA PAULA SERRA DE OLIVEIRA

Coordenadora

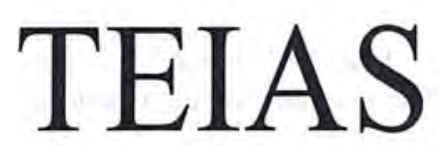

MATEMÁTICAS

Frentes na Ciência e na Sociedade 
(C) Gradiva - Publicações, L. da / Imprensa da Universidade de Coimbra, 2004 Coordenação editorial: Maria Paula Serra de Oliveira

Tradução: Artur Soares Alves

Carlota Isabel Leitão Pires Simões

Francisco José Craveiro de Carvalho

João Filipe Cortez Rodrigues Queiró

José Miguel Dordio Martinho de Almeida Urbano

Lia Sandra dos Santos

Mário da Silva Rosa

Paulo Eduardo Aragão Aleixo Neves de Oliveira

Revisão do texto: Isabel Pedrome

Capa: António Barros [Imprensa da Universidade. Coimbra], com imagem de

E. M. de Melo e Castro, "Fract 010 explod MC", Dezembro de 2003

[Fractal original gerado no Fractint com tratamento no Photoshop 7.0]

Infografia: Estúdios Estímulus [design]

Paginação: António Resende e Victor Hugo Fernandes

Impressão e acabamento: G.C. - Gráfica de Coimbra, L. da

Reservados os direitos para Portugal por:

Gradiva - Publicações, L. ${ }^{\text {da }}$ e Imprensa da Universidade de Coimbra

Gradiva - Publicações, L. ${ }^{d a}$

Rua Almeida e Sousa, 21, r/c, esq. • 1399-041 Lisboa

Telefs. $213974067 / 8 \cdot 213971357 \cdot 213953470$

Fax $213953471 \cdot$ Email: gradiva@ip.pt

URL: http://www.gradiva.pt

Imprensa da Universidade de Coimbra

Rua Antero de Quental, 195 • 3000-033 Coimbra

Telefs. 351239853110

Fax 3512398531 19 e-mail: fjrpress@ci.uc.pt

URL: http://www.imp.uc.pt

ISBN: 972-662-970-5

1." edição: Maio de 2004

Depósito legal n. ${ }^{\circ} 210431 / 04$

OBRA PUBLICADA COM O PATROCÍNIO DE:

CENTRO DE MATEMÁTICA DA UNIVERSIDADE DE COIMBRA DEPARTAMENTO DE MATEMÁTICA DA UNIVERSIDADE DE COIMBRA

FCT Fundação para a Ciência e a Tecnologia

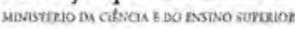


C. Borrego, A. I. Miranda, M. Lopes e A. M. Costa

Departamento de Ambiente e Ordenamento

Universidade de Aveiro

\section{Matemática e ambiente: a redescoberta dos fundamentos básicos}

\section{INTRODUÇãO}

A constatação de que a humanidade faz parte da biosfera do seu planeta contribuiu significativamente para o reconhecimento crescente da interdependência e da necessidade de proteger o ambiente, não só para a civilização actual, mas também para as gerações futuras. Um dos aspectos mais importantes, associado à complexidade dos processos ambientais, que os cientistas, os académicos, os engenheiros e mesmo os políticos são actualmente instados a reconhecer é a natureza interdisciplinar das ciências do ambiente. O rápido desaparecimento da divisão tradicional entre experimentalistas e teóricos e a colaboração activa entre as disciplinas (classicamente separadas) da física, da química, da biologia, da matemática, da informática, etc., procurando as inter-relações existentes, constitui a base do sucesso dos actuais especialistas do ambiente.

Os sistemas naturais são função de diversos factores não lineares, sendo o seu estudo mais bem sucedido quando ocorre em sistemas experimentais e numéricos, o que implica forçosamente simplificações. Apesar destas, o modelo mental que cada engenheiro do ambiente tem de um sistema necessita de ser formalizado matematicamente para se tornar operacional e útil: enquanto a física analisa o ecossistema como um conjunto de partículas e a química se preocupa com a sua composição, a 
engenharia do ambiente não só as divide em partículas vivas e mortas, como também descreve as suas principais interacções funcionais no sistema ambiental.

A procura do suporte matemático para compreender o ambiente está associada aos instrumentos disponíveis para a resolução de modelos, isto é, quer aos métodos numéricos quer aos computadores modernos. Por exemplo, os sofisticados modelos de qualidade do ar são resolvidos em potentes computadores, obtendo os engenheiros do ambiente a previsão dos episódios de poluição do ar, com uma elevada resolução espacial e temporal. No entanto, a complexidade dos processos atmosféricos ultrapassa a capacidade dos computadores actuais. Presentemente, os dados simulados resultam da aplicação de métodos numéricos na resolução de sistemas de equações às derivadas parciais, que representam os processos dinâmicos na atmosfera, aos quais se juntam alguns milhares de reacções químicas que integram os fenómenos da qualidade do ar.

Estes complexos sistemas de equações necessitam de condições iniciais e de fronteira que têm de ser fornecidas ao modelo, para que os resultados da simulação sejam tão precisos quanto possível. Estes dados podem ser o resultado de outras simulações ou podem provir de observações. Às incertezas numéricas relacionadas com os métodos numéricos e com as capacidades computacionais dever-se-ão associar as incertezas das observações referentes à precisão dos equipamentos, tempos de amostragem, médias temporais, etc. O valor final, o denominado valor «real», resulta do uso de muitas e diferentes técnicas matemáticas, tais como métodos variacionais, técnicas analíticas, estatística aplicada, etc.

A redescoberta desta ligação entre as ciências básicas, de onde emergem as ciências aplicadas - de que a engenharia é um bom exemplo -, leva a confirmar a necessidade imperiosa de dar uma formação forte e alargada em ciências ditas fundamentais aos alunos universitários. Apenas esta base científica garante tranquilidade num mundo em constante mutação e onde a interdisciplinaridade se tornou incontornável.

Este trabalho pretende dar uma perspectiva geral da utilização da matemática na engenharia do ambiente, fornecendo exemplos ilustrativos deste contributo, que, apesar de focarem essencialmente os processos atmosféricos, são também aplicáveis a qualquer outro processo ambiental.

\section{A INTERDISCIPLINARIDADE DAS CIÊNCIAS DO AMBIENTE}

O nascimento do pensamento científico, traduzido no desenvolvimento de métodos (experimental, dedutivo, demonstração pelo absurdo, etc.) que permitiram estabelecer as leis da natureza, foi um marco na racionalidade. 
A matemática constituiu desde sempre a linguagem de base e o suporte à formulação dos problemas e das suas soluções.

Dada a complexidade da natureza e dos fenómenos que a regem, o homem não tem capacidade de controlar todas as variáveis envolvidas. Este facto, aliado à tentativa de manipulação dos recursos naturais para proveito próprio, tem conduzido à degradação desses recursos e do ambiente natural. Para fazer face a esta problemática surgiu a engenharia do ambiente, com vocação para a remediação dos desequilíbrios causados nos sistemas naturais, distinguindo-se das outras engenharias pela sua capacidade integradora. De facto, os vários componentes do ambiente não são estanques; pelo contrário, são interdependentes, pelo que, irremediavelmente, qualquer alteração com impacto sobre um determinado meio terá reflexos nos outros meios: ar, água, solo e biota.

A compreensão do ambiente como um todo e dos seus componentes em particular requer um conjunto de conhecimentos que não se limitam a um ramo específico da ciência. É necessário conhecer os fenómenos físicos, os processos de transformação química e as relações tróficas que ocorrem nos ecossistemas. A figura 1 ilustra este tipo de filosofia e abordagem (Borrego et al., 2000).

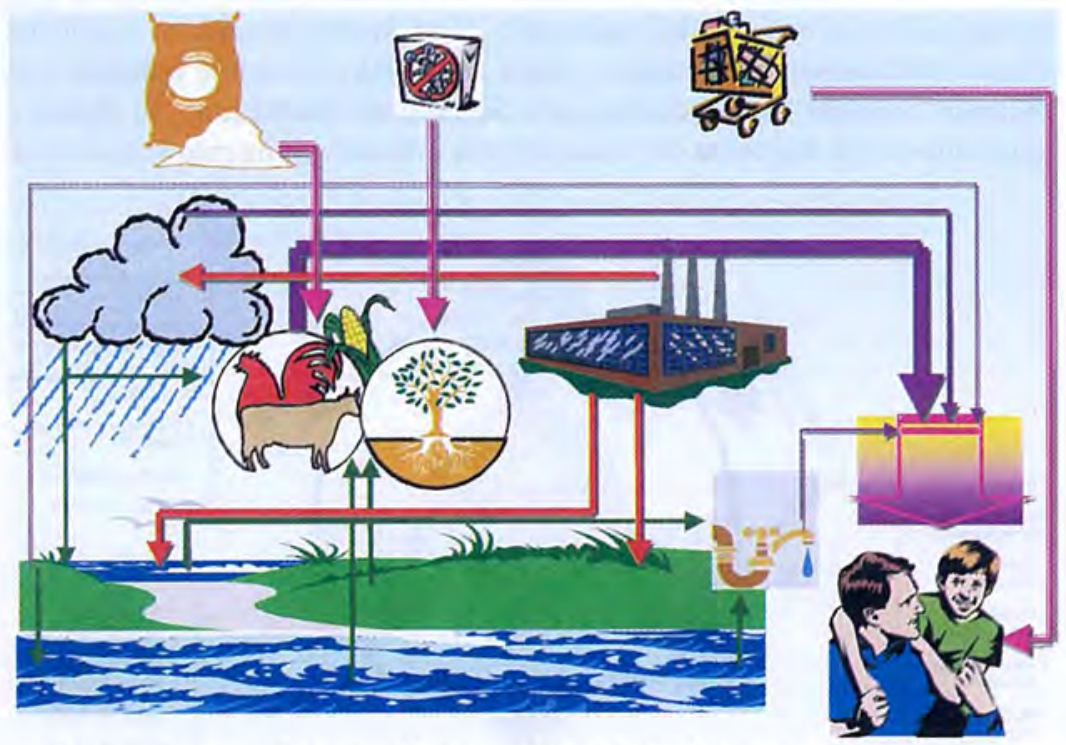

Fig. I - Esquema ilustrativo da interaç̧ão estabelecida entre o ar; a água, o solo, o biota (animais e plantas) e o homem (último elemento da cadeia alimentar) (in Borrego et al., 2000) 
Através de vários processos, tais como a precipitação, a infiltração, o escoamento subterrâneo e a evapotranspiração, estabelecem-se interacções entre o ar e a superfície (animais e plantas). Quando ocorre um episódio de poluição, todo o ciclo é afectado. Os poluentes libertados para a atmosfera poderão ser transportados e vir a ser depositados a grandes distâncias das fontes emissoras. Os efluentes líquidos contaminarão águas e solos, que por sua vez estão associados à cadeia alimentar animal.

$\mathrm{O}$ engenheiro do ambiente deverá ter capacidade para criar, modificar, valorizar e simultaneamente proteger o meio em que o homem vive, a fim de satisfazer as necessidades deste. O ensino de engenharia do ambiente deve fazer a síntese científico-técnica, mas também social e humanística, para a resolução de problemas e desenvolver a criatividade e a imaginação. A interdisciplinaridade das ciências do ambiente e da formação de um engenheiro do ambiente veio a ser confirmada, na década de 90, quando o desenvolvimento sustentável foi estabelecido como meta prioritária a nível planetário. Este implica uma perspectiva integrada para políticos e decisores, na qual a protecção ambiental e o crescimento económico a longo prazo são vistos como complementares e não como incompatíveis, em última análise mutuamente dependentes (Borrego et al., 1999a): a solução dos problemas ambientais requer recursos que apenas podem ser disponibilizados pelo crescimento económico e, por sua vez, o crescimento económico é posto em causa se a saúde humana e os recursos naturais são afectados pela degradação ambiental. Na figura 2 apresenta-se um esquema de actuação para o desenvolvimento sustentável.

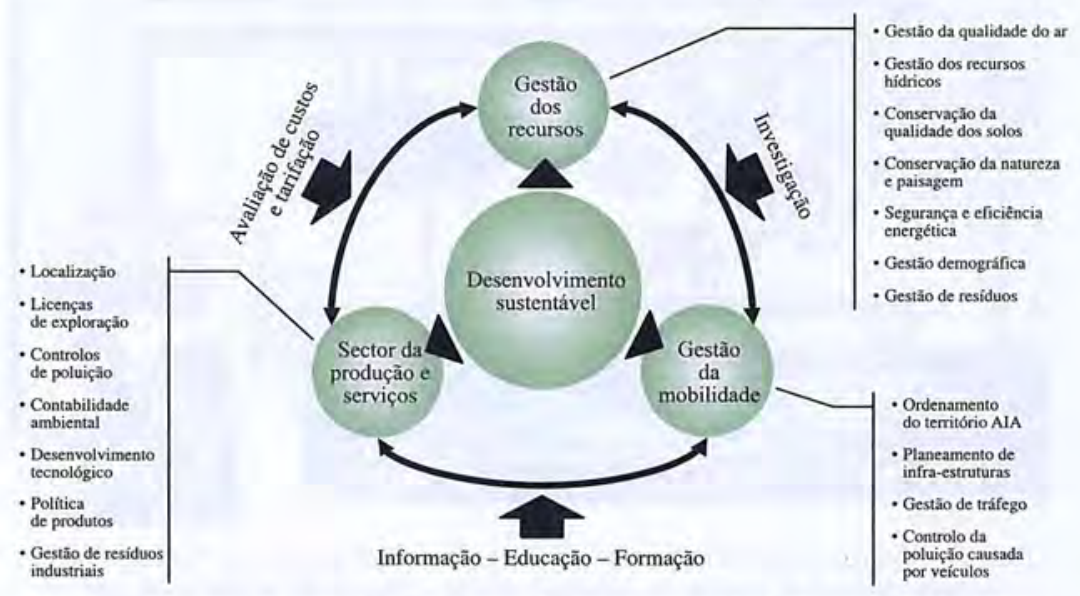

Fig. 2 - Esquema de actuação do desenvolvimento sustentável (Borrego et al., 1999a) 
O compromisso assumido recentemente, em 1997, em Quioto, pelos países industrializados, relativamente à redução das emissões para a atmosfera de gases com efeito de estufa (GEE), ilustra com clareza a forte relação entre a componente ambiente e a componente desenvolvimento sócio-económico. De facto, a tendência de evolução das emissões de GEE depende de inúmeras variáveis, tais como o desenvolvimento económico, o crescimento populacional e os padrões de consumo energético. O desenvolvimento de sectores económicos como o dos transportes, a agricultura e a gestão de resíduos tem também um papel de relevo neste processo (Borrego et al., 1999b).

Portugal assumiu como objectivo nacional o crescimento das suas emissões dos 6 GEE em $27 \%$ e de dióxido de carbono $\left(\mathrm{CO}_{2}\right)$ em $40 \%$ em relação ao ano de 1990. A verificação do compromisso assumido em Quioto implica a comparação de cenários de emissões com o inventário de base elaborado para o ano de 1990, que constitui o instrumento de análise para avaliação da eficácia da aplicação de medidas de controlo e/ou redução das emissões de GEE. Na figura 3 estão representadas as curvas evolutivas das emissões de GEE, construídas a partir dos inventários nacionais de emissões de gases para a atmosfera de 1990 até 1995 e extrapoladas até 2010 com base em diferentes cenários de crescimento médio (Borrego et al., 1999c). Nos gráficos estão ainda representadas as metas acordadas em Quioto. Estes cenários foram determinados considerando as emissões de base multiplicadas por factores de crescimento específicos para as diferentes fontes.
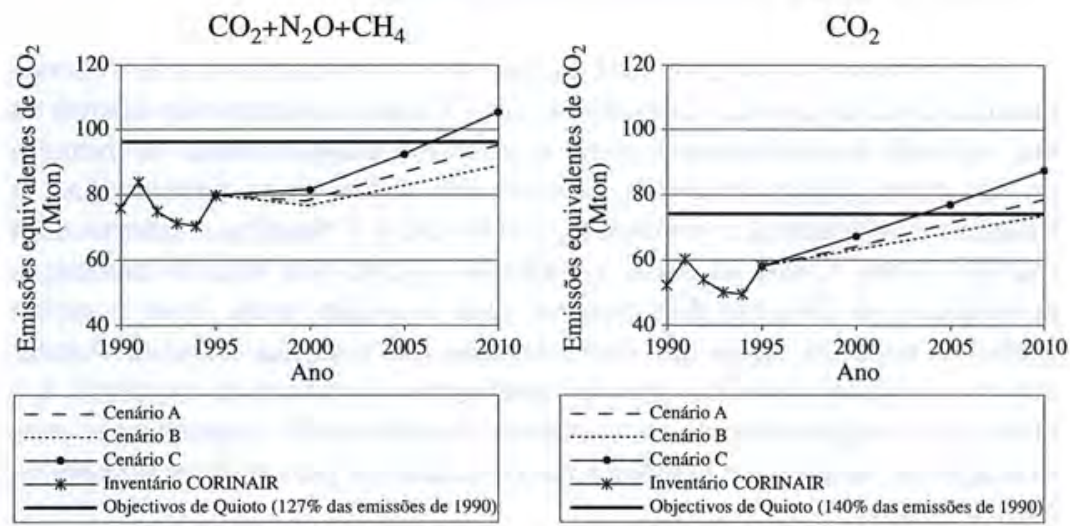

Fig. 3 - Cenários evolutivos possiveis das emissões equivalentes de GEE (Borrego et al., 1999c) 
A partir da figura 3 é possível verificar que, se o desenvolvimento do país ocorrer num cenário «business as usual» (cenário B), sem que ocorra qualquer intervenção mitigadora, é de esperar que em 2010 os limites estabelecidos para Portugal sejam atingidos ou mesmo ultrapassados. A situação torna-se mais gravosa no caso de se verificar um crescimento acima do esperado (cenário C), das actividades económicas, da população, dos requisitos energéticos do país ou mesmo uma alteração significativa do uso do solo. Nesta circunstâncias as emissões cresceriam, relativamente a $1990,64 \%$ para o $\mathrm{CO}_{2}$ e $38 \%$ para os $3 \mathrm{GEE}$, o que comprometeria significativamente o cumprimento do protocolo de Quioto.

Nos bastidores do debate político «economia e ambiente» aparece a matemática, a jogar nos dois lados deste jogo de "puxa e empurra». A matemática dá argumentos aos economistas e à sua análise financeira sobre a competitividade dos mercados, a maximização de lucros e minimização de custos, não dando no entanto resposta à questão de quantificação do custo real dos recursos naturais tendo em consideração as externalidades. A matemática dá também argumentos aos ecologistas, contribuindo para o estabelecimentos de relações de causa-efeito. Inconscientemente, toda a argumentação de base assenta em números, expressões numéricas e relações matemáticas, que contribuem para a formulação dos problemas, permitindo um conhecimento mais profundo e extenso da realidade.

\section{MODELOS MATEMÁticos: EQUACIONAR A NATUREZA PARA MELHOR CONHECER A REALIDADE}

Um instrumento fundamental da análise e compreensão dos fenómenos naturais consiste na sua tradução em leis. Tome-se o ambiente natural na sua acepção termodinâmica como o universo complementar do homem na sua abrangência holística, constituído pelos cinco subsistemas: a litosfera, a hidrosfera, a atmosfera, a criosfera e a biosfera e emerso num mar de fotões. Como se disse, o ambiente global tem sofrido mudanças acentuadas no decurso dos tempos, quer à escala local, quer à escala global. E nada faz supor que esta evolução não continue a dar-se. Assim, um dos maiores desafios que se apresentam à sociedade moderna e à ciência é compreender os mecanismos fundamentais responsáveis pela evolução do ambiente e estudar a possibilidade de prever o seu comportamento futuro.

A ciência clássica assenta no determinismo, na reversibilidade e na causalidade estrita: o futuro de um sistema está «contido» no seu presente. 
A distinção entre passado, presente e futuro seria apenas uma ilusão. Hoje experimenta-se uma mudança radical na nossa atitude. Por toda a parte se descobre a multiplicidade, a temporalidade e a complexidade.

A ciência clássica preocupava-se principalmente com a regularidade, a ordem e a estruturação dos sistemas. Ora a ordem é a excepção no universo. E a desordem é incomparavelmente mais vasta do que a coesão estrutural. Mas tem-se verificado, de facto, que a irreversibilidade pode ser uma fonte de ordem. Longe do equilíbrio podem gerar-se estruturas coerentes e ordenadas. Por outro lado, existe hoje uma compreensão muito mais profunda do comportamento dos sistemas dinâmicos, não lineares, especialmente de sistemas sujeitos a condições fronteiras de não equilíbrio.

Sabe-se que a concepção clássica, baseada na estabilidade, na regularidade e na permanência, não cobre aspectos, alguns essenciais, do comportamento dinâmico dos sistemas. De acordo com Lorenz, Saltzman, Prigogine e outros, o comportamento do ambiente só se pode compreender em termos desta nova linguagem da dinâmica dos sistemas instáveis. A sensibilidade para as condições iniciais é afinal uma manifestação de falta de previsibilidade. Esta pode ser quantificada a partir dos expoentes de Liapunov, que medem a taxa média da divergência exponencial e que permitem, portanto, avaliar os limites de previsibilidade de um sistema natural.

Por exemplo, parece que há vários regimes estacionários acessíveis à dinâmica da atmosfera. Lorenz mostrou que nos sistemas meteorológicos o inverso do expoente de Liapunov é da ordem de 2,5 dias, o que significa que o número de informações meteorológicas para a previsão do tempo aumenta exponencialmente com um factor de 2,5 dias. Por isso, a previsão na atmosfera, seja do que for, a médio prazo não será nunca possível usando métodos deterministas! O conhecimento imperfeito das condições iniciais não permite formular previsões, fora dum horizonte temporal limitado, que define a previsibilidade do sistema.

As equações matemáticas que traduzem um determinado modelo conceptual de uma determinada realidade são em muitos casos também complexas e de difícil resolução. Apesar dos progressos tecnológicos no campo da informática e da computação, a capacidade de cálculo ainda é limitada, pelo que na maioria dos casos há necessidade de recorrer a simplificações dos modelos matemáticos, com base em condições iniciais, condições limite e parametrizações. Estes dados podem ser resultado da simulação de outros modelos ou podem provir de observações. Por exemplo, os dados meteorológicos, necessários nos modelos de dispersão de poluentes na atmosfera, podem ser resultado da simulação de modelos 
meteorológicos de prognóstico ou de diagnóstico, que geram campos bi ou tridimensionais dos parâmetros de interesse (temperatura, velocidade e direcção do vento, etc.), ou, nas aplicações mais simplistas, provir de observações meteorológicas.

Um modelo simplificado, apesar das limitações da sua aplicação, as quais nunca devem ser negligenciadas pelo operador ou por quem analisa os resultados da simulação, não deixa de ser um poderoso instrumento de diagnóstico e de previsão dos fenómenos naturais.

O modelo de qualidade do ar, representado na figura 4, é um modelo de dispersão cujo objectivo é determinar o campo de concentrações $\mathrm{C}(\mathrm{x}, \mathrm{y}, \mathrm{z}, \mathrm{t})$ de um determinado poluente atmosférico provocado pela sua emissão para a atmosfera. O modelo simula as interacções das emissões de poluentes na atmosfera e o impacto resultante na qualidade do ar, utilizando como informação de base as emissões, a meteorologia, a orografia e a química da atmosfera, entre outros dados.
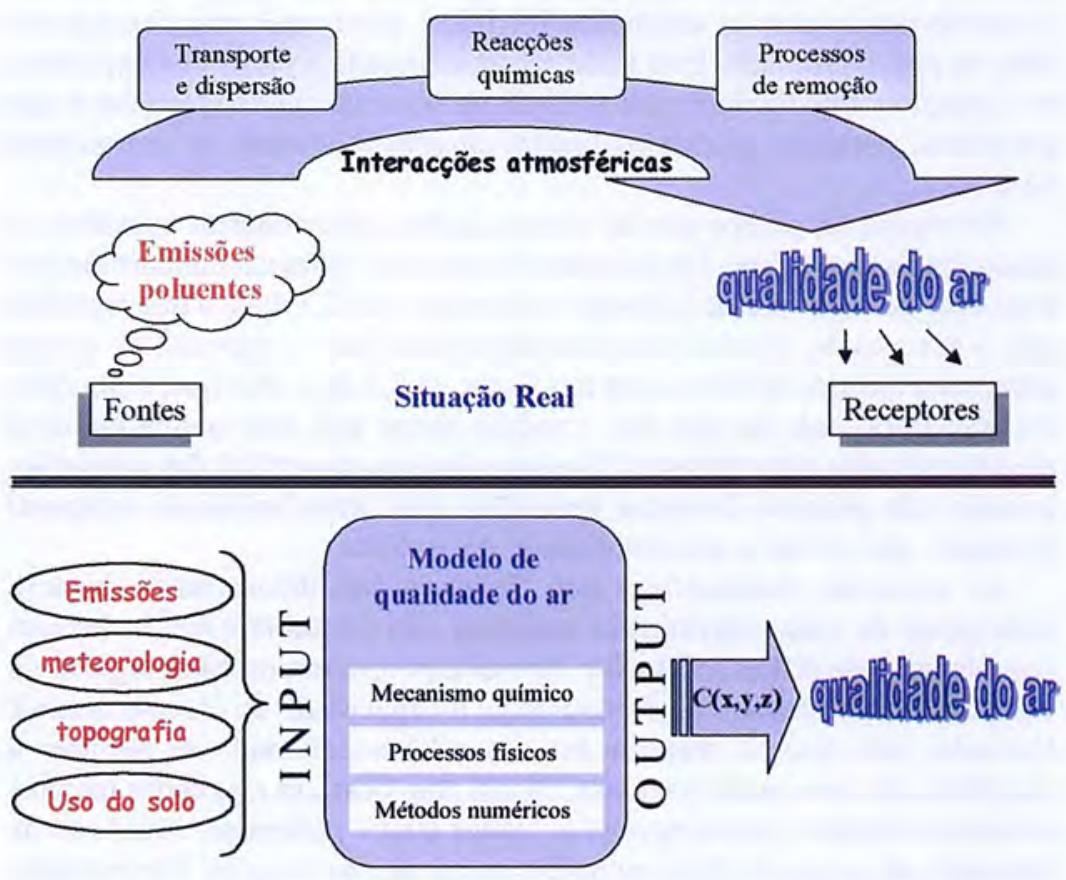

Fig. 4 - Transposição da situação real para um modelo de qualidade do ar (Borrego, 1994) 
Um outro factor a ter em conta relaciona-se com o conhecimento dessa mesma realidade. A primeira etapa de apreensão da realidade é estabelecida pelos sentidos (visão, audição, tacto, paladar e cheiro); no entanto dada a sua capacidade limitada e baixa fiabilidade, os cientistas foram desenvolvendo técnicas que permitem apreender a realidade através da medição de parâmetros característicos. Este método também é falível devido às técnicas e equipamento envolvidos, também eles limitados e falíveis. A aplicação das técnicas de análise matemática e estatística é fundamental neste processo de conhecimento, na medida em que permite estabelecer intervalos de confiança nas medições, aferir equipamentos e técnicas, tornar os dados reproduzíveis e definir os limites de aplicação dessas técnicas. A determinação de parâmetros estatísticos é um dos critérios de avaliação da qualidade dos sistemas ambientais e do cumprimento de normas legisladas.

\section{APliCaÇão de MOdelos MATEMÁticos Na COMPREensão DOS FENÓMENOS ATMOSFÉRICOS}

A poluição atmosférica, uma importante área da engenharia do ambiente, estuda os fenómenos físicos e químicos que ocorrem no meio ar, analisando as perturbações induzidas neste receptor pela introdução de gases e partículas (poluentes). Este agentes perturbadores podem ser originados por processos naturais (vulcões, erosão, floresta e outras actividades biológicas) ou por actividades humanas (fontes antropogénicas), designando-se «poluentes primários», ou resultar da transformação química ou física destes «poluentes secundários». Dependendo da intensidade da fonte, das características dos poluentes e do grau de desequilíbrio induzido pela perturbação, a atmosfera pode ter capacidade de regeneração, repondo o equilíbrio inicial, ou pelo contrário tender para um novo estado de equilíbrio.

As perturbações induzidas pelos poluentes atmosféricos, temporárias ou definitivas, têm efeitos ou impacto noutros meios (solo, água, seres vivos). A gestão da qualidade do ar, uma área de aplicação da poluição atmosférica, engloba o estudo das relações causa-efeito dos poluentes no ambiente, em particular nos seres vivos, o estabelecimento de indicadores de qualidade e a definição de medidas mitigadoras da poluição e do seu impacto ambiental. Numa perspectiva política, a gestão da qualidade do ar passa pela definição de estratégias para o recurso ar, através da escolha simultânea dos objectivos e dos meios que permitam pôr em prática essa política. 
A qualidade do ar de uma dada região, traduzida normalmente em termos de concentrações dos poluentes, depende, para além das emissões de poluentes, dos fenómenos físicos que regulam a dinâmica da atmosfera, nomeadamente o transporte ou advecção e a dispersão, das transformações químicas sofridas pelos poluentes (por exemplo processos fotoquímicos), bem como dos mecanismos de remoção desses poluentes da atmosfera (deposição seca e húmida). A qualidade do ar pode ser avaliada directamente através da medição das concentrações dos poluentes, a partir das quais se pode inferir dos efeitos agudos, crónicos ou cumulativos sobre os receptores (seres vivos, património construído, etc.). As medições directas e o seu tratamento estatístico constituem um pilar fundamental da gestão da qualidade do ar.

A modelação é um instrumento importante nos estudos de qualidade do ar. Podem distinguir-se basicamente dois tipos de modelação: física e matemática. A primeira técnica baseia-se na construção de réplicas de elementos representativos da realidade (relevo, edifícios), com base em relações de semelhança (geométrica, cinemática, dinâmica), sendo estas réplicas inseridas num túnel de vento que simula condições de escoamento semelhantes às verificadas na atmosfera. Contrastando com esta técnica, os modelos matemáticos utilizam técnicas de análise (álgebra, cálculo) para resolver directamente parte ou o conjunto de equações que traduzem o escoamento e interacções atmosféricas.

Existem vários tipos de modelos numéricos, consoante as escalas do problema que se pretende analisar e o tipo de abordagem ou de formulação do problema. Atendendo à escala espacial pode-se falar em modelos globais ou planetários, de macroscala, de mesoscala, locais ou de microscala. Em termos temporais, os modelos podem ser classificados como episódicos ou de longo termo.

A formulação matemática por detrás dos modelos é mais ou menos complexa, consoante o tipo de simplificações aplicáveis na situação para a qual o modelo foi desenvolvido. Por exemplo, a força de Coriolis, uma força existente devido à rotação da terra em torno do seu eixo, é um elemento importante no estudo das circulações de grande escala (modelos planetários e de macroscala). No entanto, o seu efeito pode ser desprezado no estudo do escoamento atmosférico de microscala pelo que as equações do movimento podem ser simplificadas por eliminação do termo correspondente. Pelo contrário, o efeito da rugosidade do solo (e das forças de atrito associadas) é um fenómeno bastante relevante em escoamentos de escala local, mas negligenciável nos de grande escala, nos quais se torna mais relevante a topografia do terreno ou o tipo de cobertura do solo. 
Os sistemas mais complexos utilizados no estudo da qualidade do ar incluem um conjunto de modelos (meteorológico, de dispersão, de emissões) e módulos de cálculo (mecanismo de reacções fotoquímicas, cálculo de deposição, cálculo de sobre-elevação de penachos, cálculo de forçamento radiativo, etc.), pré-processadores (que convertem os dados de entrada para o formato específico do modelo) e pós-processadores, que tratam os dados, por exemplo estatisticamente, de modo a facilitar a sua análise e a sua comparação como valores legislados ou com valores de referência.

O sistema de modelos MAR (Barros, 1999) é um dos sistemas complexos que permitem simular o transporte, a dispersão e a produção fotoquímica num domínio de mesoscala. A sua formulação baseia-se na resolução numérica das equações base da atmosfera, assumindo algumas simplificações que estão associadas ao tipo de escoamento simulado (mesoscala) e parametrizações (parametrização da turbulência atmosférica, por exemplo). Na figura 5 apresentam-se os campos horizontais superficiais de ventos e de concentrações de ozono obtidos através da aplicação do sistema MAR à região da Grande Lisboa, considerando um dia típico de Verão e todas as fontes emissoras localizadas nesse domínio (Borrego et al., 1999d). É interessante verificar a forma como o penacho gerado, principalmente em Lisboa e na península de Setúbal, acompanha o escoamento de brisa de mar que se desenvolve na região durante a tarde, verificando-se o transporte dos poluentes para sudeste do domínio.

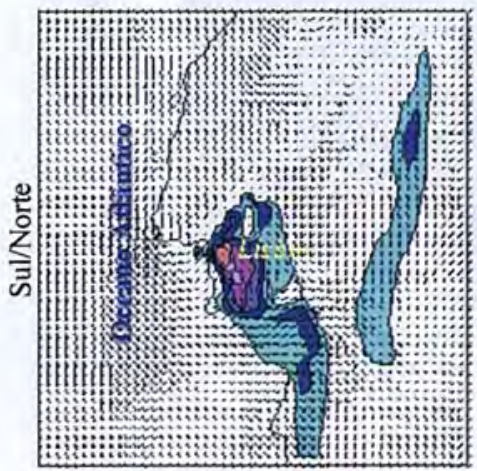

Oeste/Este

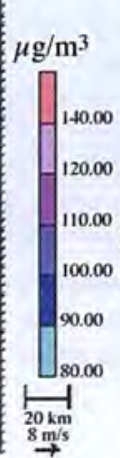

(c)

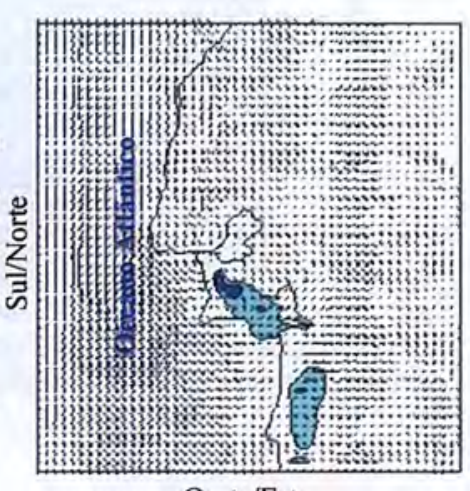

Oeste/Este

Fig. 5 - Campos de ventos e de concentração de ozono sobre a região de Lisboa, calculados pelo sistema de modelos MAR, para as $14 \mathrm{e} 18$ horas de um dia típico de Verão (Borrego et al., 1999d) 
Na figura 6 representam-se os campos de ventos e de concentração de um poluente considerado passivo, o monóxido de carbono (CO), obtidos recorrendo a um modelo local de qualidade do ar, o modelo VADIS (Martins, 1999). Neste exercício de simulação pretendia-se analisar o efeito na qualidade do ar e na saúde humana das emissões para a atmosfera de um incêndio florestal ocorrido na serra do Marvão.

Os níveis estimados de concentração de $\mathrm{CO}$ apontam para um impacto significativo na qualidade do ar. Algumas das povoações existentes no domínio de simulação poderão ser atingidas por valores de concentração desse poluente superiores aos aconselhados pela Organização Mundial de Saúde (30000 $\left.\mu \mathrm{g} . \mathrm{m}^{-3}\right)$, pelo que deverão ser considerados cuidados especiais com grupos mais sensíveis de pessoas, nomeadamente doentes, crianças e idosos.

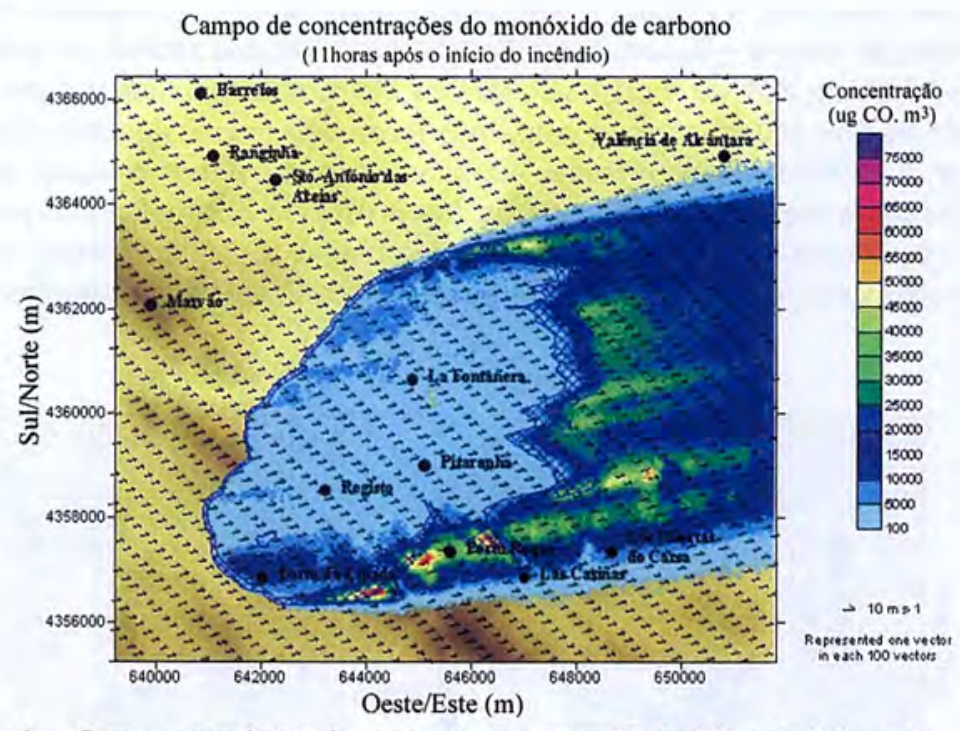

Fig. 6-Campos superficiais de vento e de concentração de CO, calculados pelo modelo VADIS, 11 horas após o inicio de um incêndio florestal na serra do Marvão

As simulações brevemente descritas e apresentadas são apenas alguns exemplos de aplicação da modelação numérica ao estudo de situações reais, e ilustram bem a importância desta ferramenta como instrumento de apoio à análise, à decisão e no desenvolvimento de cenários. 


\section{COMENTÁRIOS FINAIS}

O universo como hoje o conhecemos é um conjunto de modelos conceptuais que resultam da combinação de percepção, intuição, desenvolvimento teórico e apreensão da realidade através da medição de parâmetros característicos. Uma parte significativa desse conhecimento provém do raciocínio matemático que suporta a componente teórica e experimental da aprendizagem.

Para compreender e resolver os problemas ambientais e as suas consequências é indispensável o suporte matemático, quer na qualificação dos dados resultantes da experimentação, quer na sua descrição científica.

A aplicação de modelos matemáticos na simulação dos fenómenos atmosféricos exemplifica claramente o forte suporte da matemática para a compreensão e resolução de questões na área do ambiente.

\section{Referências}

Barros, N. (1999) - Poluição Atmosférica por Foto-Oxidantes: O Ozono Troposférico na Região de Lisboa, Dissertação apresentada na Universidade de Aveiro para obtenção do grau de Doutor em Ciências Aplicadas ao Ambiente.

Borrego, C. (1994) - Poluição Atmosférica I. Departamento de Ambiente e Ordenamento, Universidade de Aveiro.

Borrego, C., Martins, J. M. e Lopes, M. (1999a) - Instrumentos Técnico Científicos de Gestão Ambiental. $4 .^{\circ}$ Encontro Nacional de Ecologia, 2-4 de Dezembro, Portugal.

Borrego, C., Miranda, A. I., Conceição, M., Carvalho, A. C., Lopes, M. e Tchepel O. (1999b) - Climate Change and Air Quality Management: Emissions and Consequences. $6^{\text {th }}$ International Conference on Environmental Science \& Technology, 30 de Agosto-2 de Setembro, Samos, Grécia, vol. A, pp. 438446.

Borrego, C., Nunes, M., Barros, N., Portas, M. J., Monteiro, A., Lacasta, N. e Barata, P. (1999c) - A Indústria e as Alterações Climáticas. Contexto político, sócio-económico e medidas de mitigação da poluição atmosférica. AMB-QA-08/99. Relatório Final do estudo elaborado no âmbito do projecto: Universidade do Norte - Horizonte 2000. Departamento de Ambiente e Ordenamento, Universidade de Aveiro, Aveiro, Portugal.

Borrego et al. (1999d) - AMAZOC, Ambiente atmosférico em zonas costeiras: avaliação da capacidade de carga do ecossistema. Relatório científico final. Contrato PRAXIS 3/3.2/AMB/38/94. 
Borrego, C., Miranda, A. I., Coutinho, M., Ferreira, J. e Carvalho, A. C. (2000) - Air Quality Management in Portugal: Example of Needs and Available Tools. $2^{\text {nd }}$ International Workshop on Biomonitoring of Atmospheric Pollution, 28 de Agosto-3 de Setembro, Açores, Portugal.

Martins, J. M. (1999) - Dispersão de poluentes atmosféricos em condições de vento fraco. Dissertação apresentada na Universidade de Aveiro para obtenção do grau de Doutor em Ciências Aplicadas ao Ambiente. 
(Página deixada propositadamente em branco) 


\section{$\begin{array}{llllll}\text { C I E } & \mathbf{N} & \mathbf{C} & \mathbf{A}\end{array}$}

mitiram realizar com sucesso tarefas tão distintas como a programação de um voo a Marte, a previsão de resultados eleitorais, a explicação do funcionamento de alguns mecanismos do sistema nervoso, ou a abordagem critica de obras de arte e de textos literários. Da ciência à sociedade, dos grandes avanços técnicos à solidez de uma argumentação lógica, a Matemática constrói teias de uma imensa flexibilidade resultante do carácter universal da sua linguagem.

Neste livro, personalidades de diferentes universos dão o seu testemunho sobre a forma como usam as teias matemáticas para tecer a sua própria visão do mundo.

Maria Paula Serra de Oliveira é professora de Matemática na Faculdade de Ciências e Tecnologia da Universidade de Coimbra. 